Vol 11, Issue 11, 2018

\title{
ANTIFERTILITY ACTIVITY AND CONTRACEPTIVE POTENTIAL OF THE HYDROALCOHOLIC RHIZOME EXTRACT OF TRILLIUM GOVANIANUM IN FEMALE WISTAR RATS
}

\author{
SHIVAM SHARMA ${ }^{1 \#,}$ VINEET MEHTA $^{2 \#, ~ P A R U L ~ S H A R M A ~}{ }^{1}$, KRITIKA JAGGI $^{1}$, MALAIRAMAN UDAYABANU ${ }^{2}$, \\ HEMANT SOOD ${ }^{1 *}$
}

${ }^{1}$ Department of Bioinformatics and Biotechnology, Jaypee University of Information Technology, Waknaghat, Solan - 173 234, Himachal Pradesh, India. ${ }^{2}$ Department of Pharmacy, Jaypee University of Information Technology, Waknaghat, Solan - 173 234, Himachal Pradesh, India. Email: hemant.sood@juit.ac.in

\#Equal contribution (first authors)

Received: 19 May 2018, Revised and Accepted: 18 July 2018

\begin{abstract}
Objective: Trillium govanianum is used in several traditional containing steroids and sex hormones for the management of inflammation, menstrual disorders, sex-related disorders, and antiseptic. The present study was aimed to investigate the antifertility potential of hydroalcoholic rhizome extract of T. govanianum and to explore the possible mechanism of action.
\end{abstract}

Methods: Anti-implantation activity of T. govanianum rhizome extract (125 and $250 \mathrm{mg} / \mathrm{kg}$; p.o.) was performed in female Wistar rats with proven fertility, and its estrogenic/antiestrogenic effect was evaluated in ovariectomized females. $17-\alpha$-ethinylestradiol $(1 \mu \mathrm{g} / \mathrm{rat} / \mathrm{day}$; s.c.) or plant extract was administered for 11 days after which animals were sacrificed. Percentage inhibition of implantation sites, serum estrogen levels, changes in body and uterus weight, and morphological alterations in the uterus and ovaries were evaluated.

Results: T. govanianum treatment resulted in increased uterus weight and induced dose-dependent anti-implantation effect, with $100 \%$ implantation inhibition at $250 \mathrm{mg} / \mathrm{kg}$ dose. Anti-implantation effects of T. govanianum were associated with endometrial thickening and significantly elevated serum estrogen levels. Moreover, estrogenic/antiestrogenic studies revealed that T. govanianum possessed strong estrogenic effect; however, the effect was saturable.

Conclusion: T. govanianum possesses antifertility activity which can be attributed to its strong estrogenic potential and uterine thickening. Moreover, it could find a clinical application as a safer and efficacious birth control herbal remedy.

Keywords: Antifertility, Trillium govanianum, Estrogen, Anti-implantation, Steroids, Herbal remedy.

(c) 2018 The Authors. Published by Innovare Academic Sciences Pvt Ltd. This is an open access article under the CC BY license (http://creativecommons. org/licenses/by/4. 0/) DOI: http://dx.doi.org/10.22159/ajpcr.2018.v11i11.27420

\section{INTRODUCTION}

Currently available oral contraceptives are associated with several side effects such as hormonal imbalance, weight gain, hypertension, and increased risk of cancer [1], besides being expensive and not completely reliable, thus limiting their use. There is a growing need for alternative antifertility strategies which are safer, cost-effective, self-administrable, and effective. Plant-based antifertility drugs may be looked on as a potential antifertility agent for controlling global population, especially in the developing and underdeveloped nations [2].

Trillium govanianum is an important medicinal herb found at an altitude of $2400-3500 \mathrm{~m}$ in the Himalayan regions. Rhizomes of T. govanianum are a rich source of steroids, such as trillarin, which on hydrolysis yield diosgenin, a corticosteroid hormone used in the preparation of steroidal medicines and sex hormones, such as testosterone, glucocorticoids, and progesterone besides being useful in rheumatism and regulation of menstrual flow $[3,4]$. T. govanianum is used in several traditional and folk medicines containing steroids and sex hormones and for the treatment of ailments such as boils, dysentery, inflammation, menstrual disorders, sex-related disorders, wound healing, and as an antiseptic [5-7]. The antioxidant, analgesic, anti-inflammatory, anticancer, and antifungal potential of T. govanianum has been experimentally validated $[4,5,8-10]$; however, the scientific evidence to justify its antifertility potential is lacking. Therefore, the present study was aimed to investigate the antifertility potential of T. govanianum and to elucidate the possible mechanism.

\section{METHODS}

Plant collection and extraction procedure

T. govanianum plant was authenticated by Dr. Jagdish Singh, Himalayan Forest Research Institute, Indian Council of Forestry Research and Education, Ministry of Environment and Forests, Governmnet of India. Rhizomes of T. govanianum were collected from Chamba region (altitude: $3500 \mathrm{~m}$ ) of Himachal Pradesh, India, in August 2014, hydroalcoholic (30:70; water: methanol) extract (TGE) was prepared [4], and preliminary phytochemical screening was performed [11].

Animals

Wistar rats (200-250 g) were maintained under standard conditions with $21 \pm 2^{\circ} \mathrm{C}$ temperature, $60 \pm 1 \%$ humidity, and $12 \mathrm{~h} \mathrm{light/dark} \mathrm{cycle.}$ Animal was fed standard rat pellets and had free access to water. Experimental procedures were performed after approval from the Institutional Animal Ethical Committee, as per the guidelines of the CPCSEA, India.

\section{Anti-implantation activity}

Anti-implantation studies were performed in the animals with proven fertility in accordance with the procedure described by Taprial et al. (2013). These female animals were divided into three groups $(\mathrm{n}=4-6)$ : Group-1: Control (received $0.3 \%$ carboxymethylcellulose as vehicle) and Group-2 and Group-3 received 125 and $250 \mathrm{mg} / \mathrm{kg} \mathrm{TGE,}$ respectively (suspended in vehicle). All the treatments were given orally (once daily) for 11 days. On the $12^{\text {th }}$ day, animals were weighed and sacrificed, and the uterus was harvested, weighed, and examined 
for implantation sites. Ovaries and uterus were fixed in 4\% formalin for histopathological examination. Serum was extracted and used for estrogen evaluation [12].

\section{Estrogenic/antiestrogenic study}

Estrogenic/antiestrogenic effect of plant extract was evaluated in the ovariectomized female Wistar rats, as per the method described by Taprial et al. [12]. Animals were divided into six groups $(\mathrm{n}=5)$. Group-1: Control (received vehicle); Group-2 received 17- $\alpha$-ethinylestradiol (EE; $1 \mu \mathrm{g} / \mathrm{rat} /$ day; S.C.); Group-3 and Group-4 received 125 and $250 \mathrm{mg} / \mathrm{kg}$ TGE, respectively (suspended in vehicle; orally); and Group-5 and Group- 6 received 125 and $250 \mathrm{mg} / \mathrm{kg}$ TGE, respectively (suspended in vehicle, orally) along with EE $(1 \mu \mathrm{g} / \mathrm{rat} /$ day $)$. All the treatments were continued for 11 days. Animals were sacrificed on day 12, body weight changes were observed, serum was extracted, and estrogen levels were determined [12].

\section{Statistical analysis}

Results are depicted as mean \pm standard deviation. Statistical significance was determined using one-way ANOVA followed by Dunnett's multiple comparison test, using GraphPad prism 5 software. All the results were compared to control, and the statistical significance was determined at ${ }^{*} \mathrm{p}<0.05,{ }^{* *} \mathrm{p}<0.01$, and ${ }^{* * *} \mathrm{p}<0.001$

\section{RESULTS}

\section{Phytochemical screening}

Phytochemical screening of the TGE revealed the presence of alkaloids, glycosides, flavonoids, tannins, steroids, amino acids, lignin, and inulin in the extract. Volatile oil, aleurone grains, fats, and fixed oils were not present in the plant extract.

\section{Anti-implantation activity}

Results of anti-implantation effect of TGE are depicted in Table 1. Control animals demonstrated intact fertility and were observed to have 7.8 \pm 0.84 implantation sites. A number of implantation sites in TGE-treated animals were significantly $(\mathrm{p}<0.001)$ reduced in dosedependent manner. We observed $82.05 \%$ and $100 \%$ inhibition of implantation at 125 and $250 \mathrm{mg} / \mathrm{kg}$ dose, respectively. Further, TGE treatment significantly elevates serum estrogen levels, 106.72 and $216 \mathrm{pg} / \mathrm{ml}$ at $125 \mathrm{mg} / \mathrm{kg}$ and $250 \mathrm{mg} / \mathrm{kg}$ extract treatment, respectively, when compared to control $(100.84 \mathrm{pg} / \mathrm{ml})$. TGE treatment resulted in a significant $(\mathrm{p}<0.001)$ increase in uterus weight when compared to control animals. These results suggest that TGE possesses strong antiimplantation effect and may elevate serum estrogen levels.

\section{HISTOPATHOLOGY RESULTS}

Results of the histopathological examination of the uterus and ovary of the experimental animals are depicted in Fig. 1. Our results demonstrated a dose-dependent thickening of uterine endometrium wall when compared to control, which might have contributed in the anti-implantaion effect of TGE. The ovaries appeared healthy and showed morphological resemblance with control animals;, however, a slight thickening in the ovarian walls was observed in animals treated with $250 \mathrm{mg} / \mathrm{kg}$ TGE.

\section{Estrogenic/antiestrogenic study}

Estrogen levels were found to be significantly $(\mathrm{p}<0.001)$ higher in animals treated with $1 \mu \mathrm{g}$ EE when compared to control. Treating animals with TGE resulted in a significant $(\mathrm{p}<0.001)$ increase in serum estrogen level, which was observed to be $446.21 \mathrm{pg} / \mathrm{ml}$ and $436.2 \mathrm{pg} / \mathrm{ml}$ at 125 and $250 \mathrm{mg} / \mathrm{kg}$ dose, respectively (Table 1). We observed significantly $(\mathrm{p}<0.001)$ higher estrogen levels in animals treated with plant extract and EE; however, there was a significant difference between the extract treatment groups and EE group. These results suggest that TGE is having strong estrogenic effect, which appears to be saturable. Moreover, EE, TGE, and TGE+EE treatments significantly $(\mathrm{p}<0.01)$ increased the body weight and uterus weight of animals (Table 1) when compared to control.

\section{DISCUSSION}

The traditional use of herbal remedies has high fascination but lack scientific justifications, and very few remedies have been explored for their efficacy and mechanism of action [13]. Rhizomes of T. govanianum are a rich source of steroids and have been used traditionally during menstrual disorders and in the treatment of sex-related disorders in several folk medicines [5-7]. In the present study, we evaluated the antifertility effect of TGE through anti-implantation studies and investigated the potential mechanism. TGE treatment demonstrated a strong dose-dependent anti-implantation effect that could be attributed to its potential to induce endometrial thickening and estrogenic effect. Previously, anti-implantation effects of plant extract have been attributed to endometrial thickening and changes in estrogenic profile during extract treatment [12]. To investigate this possibility, we evaluated its estrogenic/antiestrogenic potential in the ovariectomized rats. Our results demonstrated a strong estrogenic effect, and the levels of serum estrogens were found to be significantly $(\mathrm{p}<0.001)$ higher than control animals. Interestingly, we did not observe any significant difference in the serum estrogen levels when control+EE animals were compared with the $125 \mathrm{mg} / \mathrm{kg}$ extract+EE and $250 \mathrm{mg} / \mathrm{kg}$ extract+EEtreated animals. To add further, there was an insignificant difference in the serum estrogen levels between different doses of extract treatment, in both EE-treated and non-treated groups. These results suggest that the estrogenic effect of T. govanianum is a saturable process. This may be explained on the basis of steroidal phytochemical, trillian, present in this plant [4], which can be converted into bioactive steroid diosgenin within the body through hydrolysis, which is a saturable process. Moreover, this gives an added advantage for the antifertility use of this plant in the clinical settings, as the estrogen levels will not increase uncontrolled and therefore side effects of antifertility agents such as hormonal imbalance could be eliminated. Our results are in agreement with the previous reports where several plant extracts, namely Afrormosia laxiflora, Pterocarpus erinaceus, Michelia champaca, and Striga orobanchioides, have been reported to possess

Table 1: Anti-implantation and estrogenic/antiestrogenic effect of the hydroalcoholic rhizome extract of T. govanianum

\begin{tabular}{|c|c|c|c|c|c|c|c|c|}
\hline \multirow[t]{2}{*}{ Treatment } & \multicolumn{5}{|c|}{ Anti-implantation study } & \multicolumn{3}{|c|}{ Estrogenic/antiestrogenic effect } \\
\hline & $\begin{array}{l}\% \text { change in } \\
\text { body weight }\end{array}$ & $\begin{array}{l}\text { Number of } \\
\text { implantation } \\
\text { sites }\end{array}$ & $\begin{array}{l}\% \text { inhibition of } \\
\text { implantation }\end{array}$ & $\begin{array}{l}\text { Serum } \\
\text { estrogen } \\
(\mathrm{pg} / \mathrm{ml})\end{array}$ & $\begin{array}{l}\text { Uterine } \\
\text { weight (mg) }\end{array}$ & $\begin{array}{l}\% \text { change in } \\
\text { body weight }\end{array}$ & $\begin{array}{l}\text { Uterine } \\
\text { weight (mg) }\end{array}$ & $\begin{array}{l}\text { Serum estrogen } \\
(\mathrm{pg} / \mathrm{ml})\end{array}$ \\
\hline Control & $5.48 \pm 0.81$ & $7.8 \pm 0.84$ & 0 & $100.84 \pm 5.21$ & $32.3 \pm 5.81$ & $0.36 \pm 0.03$ & $24.3 \pm 1.31$ & $48.255 \pm 3.58$ \\
\hline $\mathrm{EE}$ & - & - & - & - & - & $3.86 \pm 1.22 * * *$ & $62.56 \pm 6.45^{* * *}$ & $2251.38 \pm 117.25^{* * *}$ \\
\hline TG-125 & $3.64 \pm 0.3$ & $1.4 \pm 0.55^{* * *}$ & $82.05^{* * *}$ & $106.72 \pm 6.11$ & $89.51 \pm 8.11^{* * *}$ & $2.24 \pm 1.32^{* *}$ & $56.25 \pm 5.34^{* * *}$ & $446.21 \pm 29.42^{* * *}$ \\
\hline TG-250 & $4.09 \pm 0.61$ & $0 * * *$ & $100^{* * *}$ & $216 \pm 15.81^{* * *}$ & $112.21 \pm 12.11^{* * *}$ & $4.33 \pm 1.16^{* * *}$ & $72.66 \pm 7.39^{* * *}$ & $436.2 \pm 21.27^{* * *}$ \\
\hline TG-125+EE & - & - & - & - & - & $4.46 \pm 0.51^{* * *}$ & $71.46 \pm 5.21^{* * *}$ & $2922.11 \pm 110.15^{* * *}$ \\
\hline TG-250+EE & - & - & - & - & - & $4.01 \pm 1.05^{* * *}$ & $96.32 \pm 8.34^{* * *}$ & $2138.39 \pm 131.1^{* * *}$ \\
\hline
\end{tabular}

EE: 17- $\alpha$-ethinylestradiol (administered through subcutaneous injection at the dose of $1 \mu \mathrm{g} / \mathrm{rat} / \mathrm{day}$ ); TG-125: Hydroalcoholic rhizome extract of T. govanianum (administered orally at the dose of $125 \mathrm{mg} / \mathrm{kg}$ ); TG-250: Hydroalcoholic rhizome extract of $T$. govanianum (administered orally at the dose of $220 \mathrm{mg} / \mathrm{kg}$ ). ${ }^{*}$ Treatment versus control. ${ }^{*} \mathrm{p}<0.05,{ }^{* *} \mathrm{p}<0.01$, and ${ }^{* * *} \mathrm{p}<0.001$ 


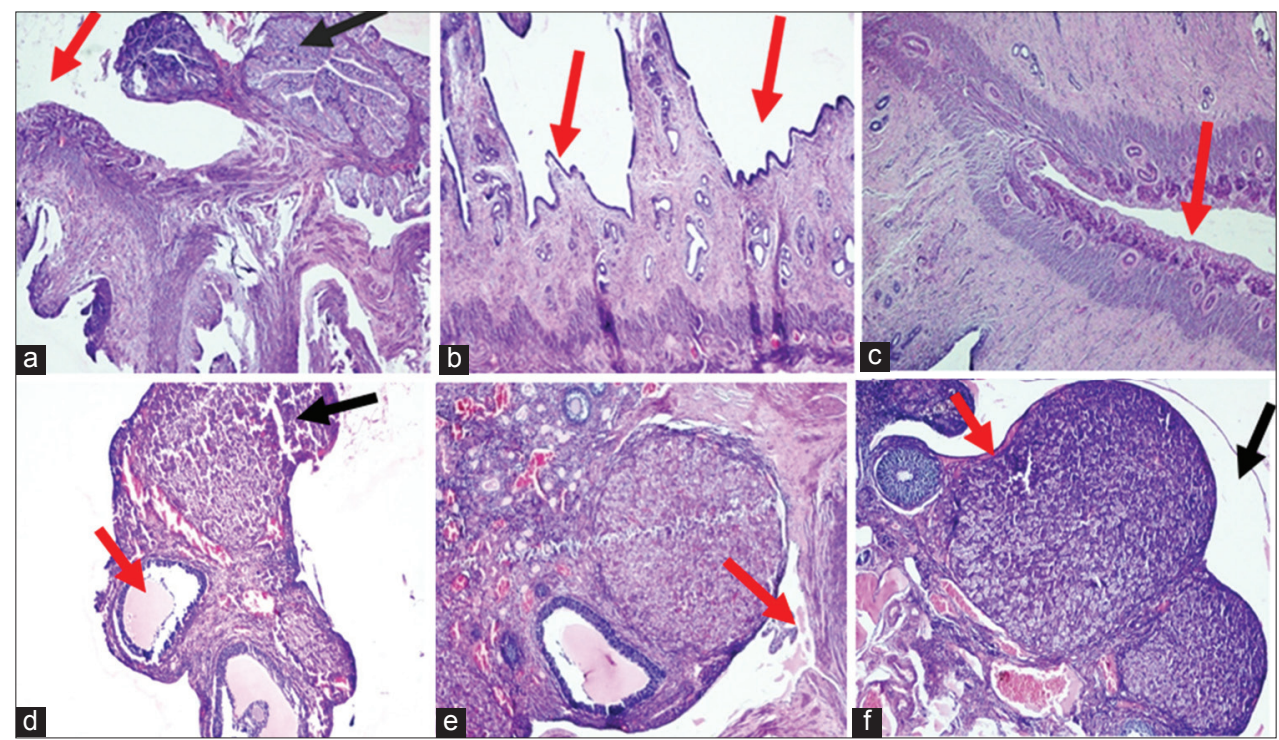

Fig. 1. Effect of hydroalcoholic rhizome extract of Trillium govanianum on histopathological changes in the uterus and ovaries of female Wistar rats. (a) uterus of control animal; (b) uterus of $125 \mathrm{mg} / \mathrm{kg}$ T. govanianum extract-treated animals; (c) uterus of $250 \mathrm{mg} / \mathrm{kg}$ T. govanianum extract-treated animals; (d) ovaries of control animal; (e) ovaries of $125 \mathrm{mg} / \mathrm{kg}$ T. govanianum extract-treated animals; (f) ovaries of $250 \mathrm{mg} / \mathrm{kg}$ T. govanianum extract-treated animals. Red arrows depict the thickening in the uterus and ovaries. Black arrow depicts normal morphology of cells in the uterus and ovaries

estrogenic activity $[12,14]$, which has been associated with antifertility properties [12]

Moreover, changes in estrogen and progesterone balance may lead to abortion or termination of pregnancy, which is the mechanism used by the clinical synthetic steroidal oral contraceptives [15-17]. Rhizomes of T. govanianum are a rich source of steroids, which can be hydrolyzed to diosgenin [4], which is used as a raw material for manufacturing synthetic steroidal contraceptives [15]. Therefore, orally administering TGE might have disturbed estrogen-progesterone balance to produced antifertility effect.

\section{CONCLUSION}

Oral administration of TGE to female Wistar rats induces dosedependent anti-implantation activity, which can be attributed to its strong estrogenic potential and uterine thickening. Estrogenic effect in ovariectomized rats was observed to be a saturable process and thereby could be free from the side effects of currently used steroidal contraceptives. T. govanianum could find a clinical application as a safer and efficient herbal birth control strategy.

\section{ACKNOWLEDGMENT}

Authors would like to acknowledge the Department of Biotechnology, Bioinformatics, and Pharmacy, JUIT, for providing all the resources to conduct this research. We would acknowledge Mr. Arun Parashar for his inputs during animal experimentation and tissue collection. We would acknowledge Nucleus Academy of Excellence, Solan, Himachal Pradesh (http://nucleas.org/), for their inputs in the manuscript preparation and editing.

\section{AUTHORS' CONTRIBUTION}

Shivam Sharma contributed in experiment design, plant collection, extract preparation and characterization, manuscript preparing, and editing. Vineet Mehta designed and performed animal experiments, result analysis, histopathology, prepared and finalized manuscript. Parul Sharma and Kritika Jaggi contributed in extract preparation, characterization, and animal experiments. Dr. Udayabanu M. and Dr. Hemant Sood designed the entire study, provided necessary funding, analyzed the results, edited and finalized the manuscript.

\section{CONFLICTS OF INTEREST}

Authors declare no conflict of interest of any kind for the study conducted.

\section{REFERENCES}

1. McNamara JO. Drugs effective in the treatment of the epilepsies. In: Hardman JG, Limbird JE, Molinoff PB, Ruddon RW, Gillman AG, editors. Goodman and Gillman's The Pharmacological Basis of Therapeutics. $9^{\text {th }}$ ed. New York: McGraw Hill; 1996. p. 461-86

2. Lembè DM, Gasco M, Gonzales GF. Fertility and estrogenic activity of Turraeanthus africanus in combination with Lepidium meyenii (Black maca) in female mice. Eur J Integr Med 2012;4:e345-51.

3. Chauhan NS. Medicinal and Aromatic Plants of Himachal Pradesh. New Delhi: Indus Publishing; 1999.

4. Sharma S, Sharma A, Mehta V, Chauhan RS, Malairaman U, Sood H. Efficient hydroalcoholic extraction for highest diosgenin content from Trillium govanianum (nag chhatri) and it's in vitro anticancerous activity. Asian J Pharm Clin Res 2016;9:386-92.

5. Khan KM, Nahar L, Al-Groshi A, Zavoianu AG, Evans A, Dempster NM, et al. Cytotoxicity of the roots of Trillium govanianum against breast (MCF7), liver (HepG2), lung (A549) and urinary bladder (EJ138) carcinoma cells. Phytother Res 2016;30:1716-20.

6. Pant S, Samant S. Ethnobotanical observations in the Mornaula reserve forest of Komoun, West Himalaya, India. Ethnobot Leafl 2010;14:193- 217

7. Rani S, Rana J, Rana P. Ethnomedicinal plants of Chamba district, Himachal Pradesh, India. J. Med Plant Res 2013;7:3147-57.

8. Ur Rahman S, Ismail M, Khurram M, Inam Ul Haq M. Pharmacognostic and ethnomedicinal studies on Trillium govanianum. Pak J Bot 2015;47:187-92.

9. Ur Rahman S, Ismail M, Shah MR, Iriti M, Shahid M. GC/MS. Analysis, free radical scavenging, anticancer and $\beta$-glucuronidase inhibitory activities of Trillium govanianum rhizome. Bangladesh J Pharmacol 2015;10:577-83.

10. Ur Rahman S, Adhikari A, Ismail M, Raza Shah M, Khurram M, Shahid M, et al. Beneficial effects of Trillium govanianum rhizomes in pain and inflammation. Molecules 2016;8:20-1.

11. Gokhale SB, Kokate CK. Practical Pharmacognosy. $12^{\text {th }}$ ed. Pune: Nirali Prakashan; 2008.

12. Taprial S, Kashyap D, Mehta V, Kumar S, Kumar D. Antifertility effect of hydroalcoholic leaves extract of Michelia champaca L: An ethnomedicine used by Bhatra women in Chhattisgarh state of India. J Ethnopharmacol 2013;147:671-5.

13. Rodriguez-Fragoso L, Reyes-Esparza J, Burchiel SW, Herrera-Ruiz D, Torres E. Risks and benefits of commonly used herbal medicines in 
Mexico. Toxicol Appl Pharmacol 2008;227:125-35

14. Hiremath SP, Badami S, Hunasagatta SK, Patil SB. Antifertility and hormonal properties of flavones of Striga orobanchio ides. Eur J Pharmacol 2000;391:193-7.

15. Tripathi KD. Essential of Medical Pharmacology. $6^{\text {th }}$ ed. New Delhi: Jaypee Brothers Medical Publishers (P) Ltd.; 2007.
16. Singh KA, Gupta RS. Antifertility activity of $\beta$-sitosterol isolated from Barleria Prionitis (L.) roots in male albino rats. Int J Pharm Pharm Sci 2016;8:88-96.

17. Singh R, Kharat SN, Mendhulkar VD. Chromatographic analysis for "diosgenin" content in Abutilon indicum (1) sweet. Int J Pharm Pharm Sci 2016;8:178-82 